\title{
Claude Lévi-Strauss por Philippe Descola \\ PHILIPPE DESCOLA (ENTREVISTA)
}

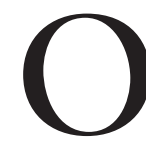

ANTROPÓLOGO francês Philippe Descola foi entrevistado por Marc Kirsch, diretor editorial da La Lettre du Collège de France, para o número especial comemorativo do centésimo aniversário de Claude Lévi-Strauss.

Philippe Descola estudou filosofia na École Normale Supérieure e etnologia na École Pratique des Hautes Études, onde defendeu sua tese, sob a orientação de Claude Lévi-Strauss. Há vários anos desenvolve uma reflexão sobre as relações entre natureza e cultura. Publicou La nature doméstique (1986), As lanças do crepúsculo (1993) e Par-delà nature et culture (2005), entre outros.

La Lettre - O senhor poderia apresentar a paisagem da antropologia francesa e o lugar que nela ocupa Claude Lévi-Strauss?

Philippe Descola - Antes da guerra, a antropologia francesa era feita sobretudo por antropólogos de gabinete - armchair anthropologists, como se dizia na Inglaterra. Nesse período, homens como Mauss ou Lévi-Bruhl na França, Frazer ou Tylor na Inglaterra dominavam massas consideráveis de dados que eles tentavam organizar para resolver um problema ou explicar uma instituição: o sacrifício, a magia etc. Há algumas exceções: alguns antropólogos já faziam etnografia, em particular Claude Lévi-Strauss, Jacques Soustelle, Denise Paulme, Germaine Tillon e alguns outros. Era um núcleo bem pequeno, comparado ao que já se fazia de maneira sistemática na Inglaterra e nos Estados Unidos.

Num segundo período, as pesquisas etnográficas se multiplicaram, mas na ausência de uma estrutura orientada tendo em vista uma inteligibilidade antropológica geral. A ação de Lévi-Strauss contribuiu para fundar um terceiro período, nos anos 1960, em que a reunião das experiências etnográficas de um conjunto de pesquisadores competentes em áreas culturais particulares permitiu fazer avançar a reflexão antropológica geral.

De fato, no seu exílio forçado nos Estados Unidos, durante a guerra, LéviStrauss descobriu os autores americanos e com eles uma prática da antropologia muito diferente da que prevalecia na França. Ao retornar a esse país, ele revolucionou a antropologia não apenas porque abordava questões novas - em particular as questões de parentesco, que permaneciam inexploradas na antropologia francesa -, mas igualmente porque suas ideias sobre os métodos de trabalho e de colaboração entre pesquisadores podiam resultar em grandes projetos de 
pesquisa, o que contrastava com os costumes solitários da antropologia francesa. Portanto, sua contribuição se deve tanto ao caráter inovador de suas ideias quanto à orientação que ele deu à institucionalização da disciplina, primeiro no Museu do Homem, depois na V ${ }^{\underline{a}}$ seção da Escola Prática de Altos Estudos e também na VI âa seção - transformada a seguir na Escola de Altos Estudos em Ciências Sociais -, e por fim no Collège de France, onde criou o Laboratório de Antropologia Social.

Esse laboratório era uma verdadeira novidade. Havia na época poucos etnólogos nas universidades e no CNRS. Em sua maior parte, eles haviam adotado a metodologia de pesquisa britânica fundada em "trabalhos de campo" de longa duração e assim estavam seguidamente em missão. Havia muito poucos instrumentos de pesquisa coletivos, as bibliotecas estavam em mau estado, a do Museu do Homem, abandonada. Não se tinha o hábito de trabalhar em comum e trocar informações provenientes das sociedades do mundo inteiro - o que teria sido possível em princípio, pois se dispunha de etnógrafos especialistas da maior parte das regiões do planeta. Ao criar o Laboratório de Antropologia Social, Lévi-Strauss fez a aposta de que era possível fazer antropologia como se fazem as ciências experimentais, isto é, de forma coletiva. E ao escolher o nome laboratório, quando o costume teria imposto instituto ou um equivalente, ele queria sublinhar esse caráter de pesquisa coletiva. Evidentemente não seriam realizadas experiências nesse laboratório, mas a combinação das experiências etnográficas individuais de seus membros seria um trunfo para tentar responder a questões gerais de ordem teórica.

Desse ponto de vista, Lévi-Strauss marcou a antropologia. Aliás, ele não foi exatamente o único, pois de forma paralela, na Universidade de Nanterre, um africanista, Éric de Dampierre, outra grande figura da antropologia francesa, criou na mesma época um laboratório de etnologia e de sociologia comparativa, outro grande lugar de pesquisa generalista.

Assim, Lévi-Strauss, que tendem a descrever como um solitário, uma figura de grande pensador - que ele é, sem dúvida nenhuma -, desempenhou também um papel institucional importante na estruturação dos dispositivos de pesquisa em antropologia na França. Há uma outra imagem a retificar. Tende-se a associar Lévi-Strauss com as sociedades sem escrita - com o primitivismo, segundo os mais críticos. Em realidade, ele esteve na origem das primeiras pesquisas etnográficas sobre as sociedades complexas, pois dirigiu uma pesquisa conduzida por Lucien Bernot, um membro do laboratório que se tornou a seguir professor no Collège de France. Esse trabalho precursor, intitulado "Nouville, uma aldeia francesa", foi realizado bem antes da moda das monografias desse tipo. Uma outra pesquisa realizada por Pierre Clément tinha por objeto Vienne-Isère, na França. Na época, somente os sociólogos faziam trabalhos desse tipo: eles eram completamente atípicos em etnologia. Portanto, Lévi-Strauss sublinhou, muito cedo, o interesse do método etnográfico para compreender as realidades mais contemporâneas. 
A seguir, a partir dos anos 1960, vimos desenharem-se na França duas orientações diferentes. Alguns se voltaram para a antropologia fundamental tal como Lévi-Strauss propusera seus princípios e que tentava compreender as propriedades formais da vida social fazendo variar os contextos, mas num nível elevado de generalidade teórica. Outros estavam mais interessados pelas dinâmicas de transformação, mutações, rupturas, numa perspectiva mais sociológica, no sentido tradicional do termo. Eles se interessavam pelas diferentes forças que concorriam, tanto no mundo ocidental como nos países em desenvolvimento, para as transformações dos hábitos, dos sistemas sociais etc. A história tem um papel importante para compreender essas dinâmicas de transformação em longo prazo. Pode-se associar essa segunda corrente ao nome de Georges Balandier, por suas pesquisas na África e pelos trabalhos que suscitou. Trata-se aí de orientações gerais: encontramos entre as duas toda uma gama de posições intermediárias ou cruzadas.

A partir dos anos 1970, o marxismo desempenhou um papel importante em todas as ciências sociais, com variedades que correspondem a diversas leituras de Marx. Havia uma tensão muito interessante entre o estruturalismo e o marxismo, ou, talvez, a dialética em geral. Foi uma época de debates abundantes e muito intensos. A diversidade dos conceitos e das teorias levava a confrontos, mas também a tentativas de conciliação. Na França, as pessoas se definiam essencialmente em relação ao estruturalismo, segundo seu grau de adesão ou de rejeição. Claro que era difícil estar integralmente de acordo com o conjunto das proposições de Claude Lévi-Strauss, isto é, ao mesmo tempo o método estrutural e sua filosofia amplamente explicitada da vida social. Havia assim um leque muito amplo de posições.

Para concluir esse sobrevoo histórico, convém acrescentar que essa institucionalização da antropologia conheceu um tal sucesso que a França se tornou o país da Europa em que mais havia etnólogos. Na Inglaterra, o outro grande país da etnologia, o financiamento das universidades foi drasticamente reduzido na época de Margaret Thatcher. Com isso, a etnologia francesa se viu numa situação muito favorável. Um grande número de jovens pesquisadores encontrou condições de partir para minuciosos trabalhos de campo, com meios para aprender as línguas e tempo para fazer longas estadas e explorar a seguir seus materiais. Paradoxalmente, essa situação privilegiada conduziu a uma espécie de retrocesso da teoria antropológica, porque de repente os pesquisadores tiveram acesso a uma tal quantidade de materiais que se viram desencorajados a fazer grandes sínteses. Além disso, o desenvolvimento das concepções pós-modernas levou a teorizar essa impotência de fato. Proclamava-se que a época das grandes teorias havia terminado, que era preciso contentar-se em tentar compreender as condições de produção de enunciados científicos válidos a propósito deste ou daquele fato numa sociedade dada, e que era impossível ir mais longe. Houve assim uma concentração na erudição - que é uma qualidade, mas que se torna estéril quando é um fim em si mesma. 
Lévi-Strauss sobre as pedras do Rio Pimenta Bueno (RO).

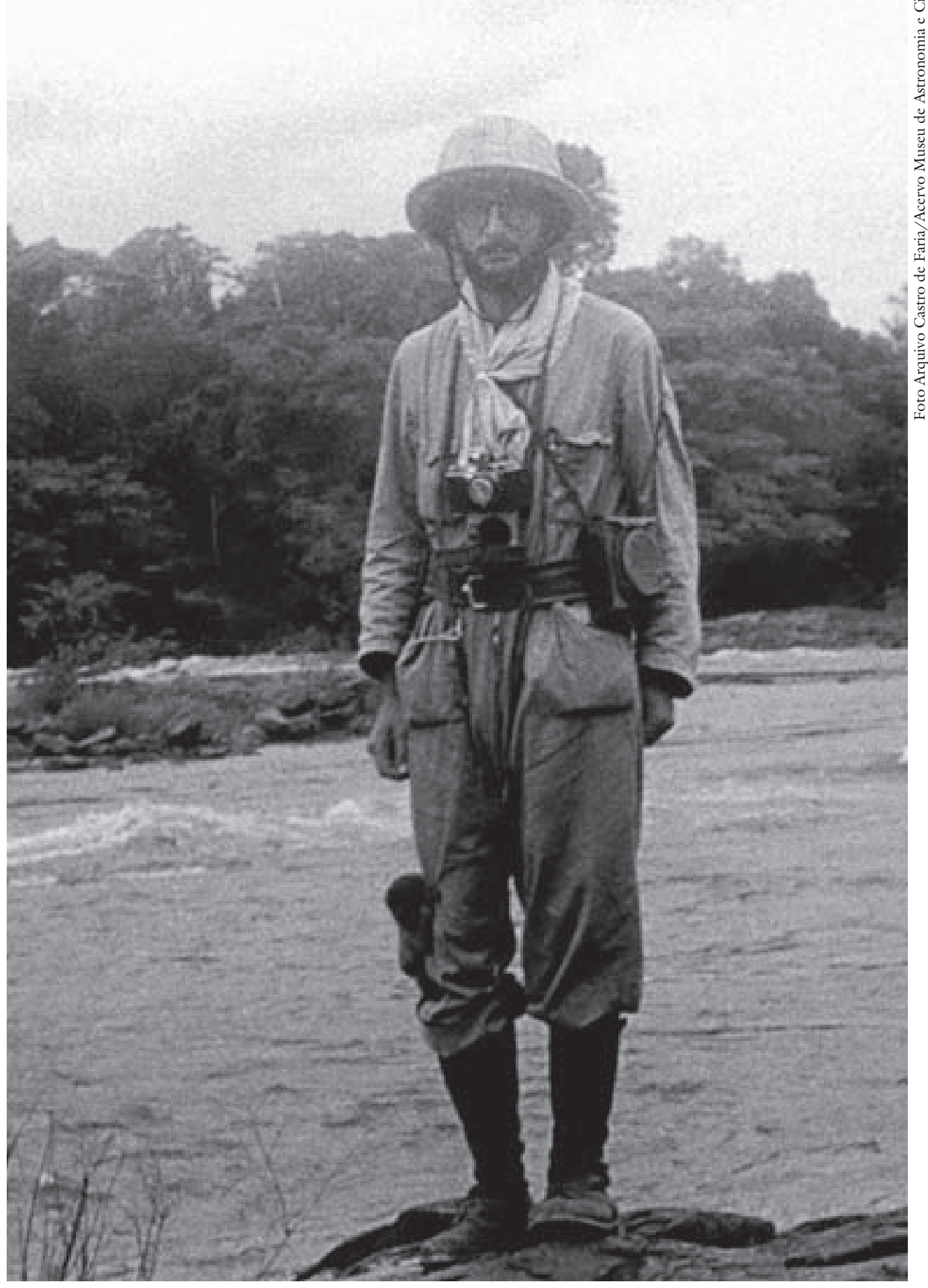


Estamos atualmente saindo desse período. As ciências cognitivas provavelmente desempenharam nesse ponto um importante papel, porque os pesquisadores que as invocavam foram os primeiros a terem a audácia de fazer novamente proposições gerais. Depois de ficarem por muito tempo marginalizados, eles acabaram por se fazer ouvir. A antropologia cognitiva e, de uma maneira geral, as ciências cognitivas se apoderaram de temas que, desde o final do século XIX, eram os da antropologia comparada e que foram aos poucos retomados por outras disciplinas. Hoje esses problemas parecem seguidamente escapar aos antropólogos, que se concentraram no acúmulo de conhecimentos locais em detrimento de sínteses mais ambiciosas. Ora, a antropologia deve poder manter as duas coisas: uma erudição impecável e teorias gerais, hoje com frequência deixadas para outros. Assim como os historiadores estão acostumados à crítica das fontes, os antropólogos sabem utilizar as fontes etnográficas, avaliar sua confiabilidade etc. Não se deve negligenciar o savoir-faire dos antropólogos - ainda que às vezes eles sejam reticentes em utilizá-lo a fim de não recolocar grandes questões que julgam demasiado gerais.

La Lettre - O que ocupon o lugar das ciências cognitivas para Lévi-Strauss? A psicanálise parece-lhe ter sido, no inicio, um terreno sólido onde apoiar-se para compreender o funcionamento do espirito.

$P D$-Lévi-Strauss disse que a psicanálise foi uma de suas três amantes. Ele conhece bem Freud, serviu-se de alguns conceitos da psicanálise aos quais dava crédito, mas não da psicanálise como tal. Lévi-Strauss é muito naturalista. Eu não diria que é cientificista, mas que ama a ciência. Quando criou o laboratório, ele fez uma assinatura da revista Science. Também lia regularmente Nature. Mantém-se informado das descobertas da ciência, como vemos em sua obra. Se escrevesse hoje, falaria de neurônios-espelho e de genômica. Para ele, a antropologia deve necessariamente aproveitar os resultados das outras ciências que produzem saberes sobre o homem.

La Lettre - Ele serviu-se muito da linguística.

$P D$ - Ela serviu de modelo e de fonte de inspiração. Mas Lévi-Strauss lia também psicologia. Conhecia Piaget, um autor importante nesse domínio. Ele sempre quis se manter a par do estado das pesquisas, porque, para estudar uma espécie tão complexa como a nossa, é preciso mobilizar uma grande quantidade de conhecimentos sobre seus diferentes aspectos. Uma das críticas que se podem fazer a muitos antropólogos é ter negligenciado as contribuições da psicologia. Se nos interessamos pelo humano, não podemos negligenciar o que a psicologia cognitiva nos ensina sobre os mecanismos do raciocínio, da percepção, da memória ou da localização espaciotemporal.

La Lettre - Será que Lévi-Strauss não tem aqui uma parte da responsabilidade, na medida em que Raça e história era uma forma de romper com uma antropologia fisica que o evolucionismo reintroduz e que os antropólogos não apreciam? A ideia de que a cultura é um fenômeno sui generis está muito enraizada 
nos que estudam os fenômenos sociais: eles consideram que as coerções naturais ou biológicas não devem ser levadas em conta porque a cultura compõe um mundo que se subtrai a essas coerções.

$P D$ - De fato, a antropologia física é malvista, mas há um abismo entre suas versões antigas e os estudos finos que se podem fazer hoje sobre os mecanismos do raciocínio ou da navegação no espaço. E realmente, para uma grande maioria de antropólogos no mundo, a cultura é um fenômeno sui generis. No entanto, não se pode afirmar que a humanidade é uma esfera completamente autônoma e separada do resto dos não humanos, quando toda uma continuidade filogenética nos liga a eles e quando não cessamos de descobrir em novas espécies animais novos traços comportamentais variáveis e não geneticamente transmitidos ("culturais", portanto). É preciso reconhecer, em sentido contrário, que os excessos do culturalismo se alimentam dos excessos do naturalismo. Trabalhos que tomam a Amazônia ou o Kalahari como campo de pesquisa com a ideia - evidentemente tácita - de que lá, sendo a cultura menos complexa, se encontram com mais facilidade invariantes biocomportamentais, suscitam a hostilidade dos antropólogos, que lembram que esses povos têm uma história de 15 mil anos que não se pode passar em silêncio. Nos Estados Unidos, quiseram manter os four fields, isto é, a colaboração das quatro disciplinas: Linguística, Antropologia Social, Antropologia Física e Arqueologia. Essas quatro disciplinas estão ligadas e cada uma requer conhecimentos nas outras três. É preciso acrescentar a elas a Etologia dos Primatas Superiores. Mas em realidade só foi mantida a ficção dos four fields: há departamentos em que especialistas dessas disciplinas se aproximam, mas sem uma interação verdadeira. A interdisciplinaridade é difícil. É preciso começar por ler o que os outros fazem. De minha parte, interesso-me muito pelos trabalhos de McGrew sobre a etnografia comparada dos chimpanzés, pelos de Tomasello em psicologia, que compara a cognição no homem e nos grandes macacos etc.

\section{La Lettre - O que caracteriza a abordagem estrutural em antropologia?}

$P D$ - Jean Pouillon deu uma boa definição ao dizer que se é realmente estruturalista quando se tem o interesse menos pelas semelhanças do que pelas diferenças que se buscam ordenar de forma sistemática. Parece banal, mas acho bastante justo. O estruturalismo põe o acento não apenas nas diferenças no interior de um sistema, mas na ideia de que essas diferenças diferem de maneira sistemática e de que todo o trabalho de inteligibilidade da vida social consiste em valorizar esse caráter sistemático da diferença das variações. Toda a obra de Lévi-Strauss ilustra essa ideia. Essa abordagem obriga a escolher unidades de observação de um tipo particular, muito diferentes das que se tomam na antropologia inglesa ou americana. Na antropologia inglesa, a unidade de observação é a sociedade, society: o interesse é por um sistema de relações sociais. $\mathrm{Na}$ antropologia norte-americana, herdeira nesse ponto da antropologia alemã, é a cultura. Também aí se trata de um conjunto fechado caracterizado por uma 
história, uma língua, uma religião, um sistema de crença. São objetos empiricamente definíveis, enquanto a unidade de trabalho do estruturalismo é um grupo de transformação. É a escolha do analista que determina quais elementos vão constituir o grupo de transformação. Nesse caso, a unidade não tem existência empírica: pode ser uma escala de comparação, uma escala regional etc., escolhida por sua pertinência em relação ao fenômeno estudado.

Assim, enquanto na antropologia inglesa ou americana o trabalho teórico se faz por generalização indutiva a partir dos dados etnográficos, na antropologia estrutural o método é antes dedutivo ou hipotético-dedutivo: começa-se por definir a unidade de observação e de análise em razão do problema colocado. É um procedimento completamente diferente. Por isso, há frequentes malentendidos entre a antropologia anglo-saxã e a antropologia francesa. Há uma verdadeira dissociação entre o trabalho de interpretação etnográfico e o trabalho antropológico, que se situa numa escala diferente. Claro que a disjunção não é absoluta. O material antropológico que utilizamos nunca está completamente purificado das condições de sua obtenção: carrega consigo o vestígio dos contextos, das situações de observação e de enunciação etc. Diferentemente de uma tabela periódica dos elementos, não se podem descontextualizar completamente as peças elementares - mesmo se essa ambição persiste.

La Lettre - Para Marx, o real são as estruturas, coisas que são da ordem da sociedade. É bastante diferente para o naturalista inspirado no evolucionismo biológico. De que lado se situa Lévi-Strauss? A posição dele variou sobre essa questão?

$P D$ - Suas ideias provavelmente evoluíram, mas penso que o importante para ele é compreender as leis do pensamento: é o ponto fundamental do qual deriva todo o resto. Essa convicção está presente muito cedo. Se Lévi-Strauss se interessou inicialmente pelas instituições, é porque desde As estruturas elementares do parentesco, seu primeiro grande livro de teoria sociológica, ele faz a hipótese de que os elementos principais da vida social são espécies de imperativos cognitivos. O estudo dos produtos do pensamento, das classificações, dos saberes ecológicos, dos mitos etc. vem a seguir, motivado pela ideia de que as combinatórias institucionais que ele estudou são talvez simplesmente o resultado do jogo da vida social, uma objetivação de propriedades da interação social que é difícil ligar às leis do pensamento. Para compreendê-las, convém então ir a montante, rumo ao intelecto, para usar a fórmula que lemos em $O$ totemismo hoje, e passar das instituições aos enunciados e, em particular, aos mitos. De fato, nos mitos o espírito se desdobra, de certo modo, toma-se a si mesmo como matéria e brinca consigo mesmo.

La Lettre - Nas correntes evolucionistas, buscam-se invariantes próprios a uma espécie. Lévi-Strauss parece antes buscar diferenças ou um sistema de diferenças - que certamente pode ser considerado ele mesmo um invariante: afinal, a proibição do incesto é uma espécie de invariante. Mas sua formalização ou sua formulação cultural constitui um conjunto de diferenças, uma combinatória. 
$P D$ - De fato, a diferença é claramente marcada. A antropologia cognitiva teve talvez uma tendência a derivar para os problemas colocados pela psicologia, que é mais orientada para a busca dos universais, enquanto a antropologia no sentido de Lévi-Strauss busca invariantes, isto é, maneiras sistemáticas de variar, mas não universais. Para um antropólogo, é útil ter um saber sobre os universais, mas não é o papel da antropologia buscá-los. Cabe à psicologia, à linguística, à ergonomia e a outras disciplinas relacionadas às ciências do homem trabalhar sobre essa questão.

La Lettre - Não é o que o senhor faz ao definir os esquemas de pensamento que distingue: animismo, totemismo, naturalismo, analogismo?

$P D$ - Esses esquemas constituem um grupo de transformação, mas estendido à escala de toda a humanidade. É um instrumento gerador, um dispositivo experimental que me permite captar uma certa classe de fenômenos e distribuílos de maneira racional. Para que se possa falar de universais no presente caso, seriam necessárias provas experimentais.

Segui o caminho traçado por Lévi-Strauss, que consiste em partir da observação das instituições e das sociedades para obter ensinamentos sobre o funcionamento do humano. Por meio de seus efeitos presumidos nas instituições, nos enunciados, nas práticas etc., remontei a um dispositivo inferencial - ele comporta quatro grandes inferências de base. Faço a hipótese de que esse dispositivo existe, descrevo sua forma, depois examino de maneira detalhada suas consequências nos diferentes domínios da vida social. Eu gostaria de trabalhar com psicólogos do desenvolvimento, por exemplo, para examinar se há uma consistência psicológica nesses mecanismos inferenciais. Se for o caso, a psicologia terá dado a esse dispositivo uma espécie de validade, com a condição de que a base experimental seja suficientemente ampla e os protocolos experimentais suficientemente finos para acomodar as variações culturais. Eu ficaria feliz com um tal resultado, é claro. Mas não foi uma busca de universais que guiou o meu trabalho.

La Lettre - Mesmo assim são trabalhos que têm uma dimensão filosófica evidente. Não é por essa razão que filósofos como Ricoeur e Lévinas, por exemplo, atacaram Lévi-Strauss? E como explicar esse mal-entendido recorrente que levou a acusarem-no de formalismo e de anti-humanismo?

$P \boldsymbol{P}-$ É verdade que houve uma tendência, fora da França, a classificar Lévi-Strauss entre os autores filosóficos. É preciso reconhecer que se trata de um pensamento que atinge um nível de complexidade inigualado em antropologia e que, de fato, tem a ver com uma maneira de colocar os problemas informada, no ponto de partida, por questões filosóficas, seja para diferenciar-se delas, seja para reformulá-las à luz do material humano com o qual se ocupa. Por esse motivo, ele suscita muitos mal-entendidos, por ser um pensamento muito difícil, com articulações conceituais complexas. Há páginas extraordinárias e complexas de Durkheim, em particular em Asformas elementares da vida religiosa; há também 
páginas complexas de Lévi-Bruhl, mas é raro que uma obra inteira se mantenha num nível de exigência tão elevado. Acrescente-se a isso a tecnicidade da própria disciplina: assim, Lévi-Strauss é um autor realmente difícil, apesar da impressão de facilidade que oferecem textos como Raça e história ou Tristes trópicos, que são falsamente transparentes.

Mas convém não se enganar: o que Lévi-Strauss faz é ciência, com um regime de verdade e de tratamento dos enunciados inteiramente distinto do da literatura ou da filosofia. A questão do sentido do destino individual não é um problema que ele aborda nos seus livros. O problema do sujeito, do mal etc., essas questões filosóficas e morais muito antigas na tradição judaico-cristã levantadas por Lévinas, por exemplo, não têm pertinência na perspectiva antropológica que Lévi-Strauss desenvolve.

La Lettre - No entanto, percebe-se claramente nele uma inquietação com a espécie, uma desaprovação da maneira como ela se comporta e uma desconfiança em relação ao "sujeito".

$P D$ - Ele faz pensar nos moralistas do século XVIII - aliás, até na maneira de escrever, que oscila, conforme os textos, entre Montesquieu e Rousseau, de um lado, e Chateaubriand, de outro, pela economia de meios ou pelo uso do lirismo. E é sensível à ideia de uma responsabilidade coletiva. Não está muito interessado em pensar o indivíduo. Para ele, os humanos são seres mergulhados em instituições coletivas. Claro, alguns indivíduos saem do comum - ele é um exemplo -, mas a ideia do sujeito individual the é bastante alheia. Nesse sentido ele vai contra a corrente da filosofia da sua época, contra Sartre etc. Há nele uma visão profundamente pancósmica, uma espécie de panteísmo ateu, se posso dizer. Em vários momentos ele escreveu que é spinosista. O indivíduo é um elemento do mundo no qual o mundo se reflete, daí as páginas extraordinárias das Mitológicas.

La Lettre - Lévi-Strauss em Raça e história e o senhor mesmo em Par-delà nature et culture [Para além da natureza e da cultura] adotam uma postura de neutralidade em relação às diferentes culturas de que falam. Pode-se objetar que essa neutralidade é impossivel, porque sempre se escreve de um ponto de vista particular, segundo um modo de racionalidade dado, no caso ocidental e naturalista. É impossivel não fazer julgamentos sobre o fato, por exemplo, de haver modos de pensamento mais eficazes que outros, estruturações da sociedade que permitem uma influência mais operatória sobre o mundo e que garantem melhor a sobrevivência dos indivíduos e das sociedades - num prazo difícil de avaliar. Não haveria em Lévi-Strauss a ideia de que, no pensamento ocidental, a ciência e a técnica que conferem tanto poder são eficazes para os individuos e para as sociedades, e desastrosas para a humanidade, que elas estariam talvez em via de destruir?

$P D$ - Com certeza, e a acusação de relativismo moral que chegaram a fazer contra Lévi-Strauss é absurda. Poucos autores escreveram com tanta inteligência, profundidade e afeição sobre algumas das grandes e mesmo não tão 
grandes obras da cultura ocidental. O que ele escreveu sobre Un chapean de paille d'Italie, por exemplo, mostra que ele sabe também apreciar a inteligência e a complexidade de um Labiche. Houve um momento em que o relativismo dos antropólogos foi estigmatizado, Lévi-Strauss sendo visto como o principal responsável. Mas não foi a antropologia que inventou o relativismo - o qual é apenas um método de investigação dos fatos e não uma postura moral. A noção é bem mais antiga: os historiadores foram os primeiros a empregá-la.

Por sua vez, é verdade que Lévi-Strauss, mesmo procurando ser o menos etnocentrista possível, não pode abandonar a ideia de que algumas formas de pensamento são, sob diferentes aspectos, mais eficazes que outras, em particular para o tipo de empreendimento no qual ele mesmo e os antropólogos se envolveram, para explicar variações nos usos do mundo pelos humanos. Sim, algumas formas de pensamento são mais eficazes que outras, é uma constatação. Essa eficácia, em minha opinião, será tanto maior quanto tivermos - nós, ocidentais - conseguido identificar em nossas formas de pensamento o que é mais específico à nossa própria civilização, atingindo uma universalidade livre de todos aqueles sedimentos superpostos ligados ao caráter específico da nossa trajetória histórica. Esse é um desafio muito importante para as ciências humanas e sociais. Os matemáticos, os físicos ou os biólogos não enfrentam o mesmo tipo de problema, ou não de forma tão aguda. De fato, nossos conceitos, nossos próprios quadros de pensamento são ainda completamente tributários da cosmologia que engendramos e desenvolvemos não faz tanto tempo assim. Esse é o verdadeiro desafio, e não há nenhum relativismo aí.

Philippe Descola é professor do Collège de France e titular da Cátedra de Antropologia da Natureza desde 2000. Foi orientando de Lévi-Strauss. @ - descola@ehess.fr

Publicado em Hors Série - La Lettre du Collège de France, Claude Lévi-Strauss - Centième anniversaire, Novembre 2008. Entrevista concedida a Marc Kirsch. Tradução de Paulo Neves. O original em francês - "Claude Lévi-Strauss vu par Philippe Descola" - encontra-se à disposição do leitor no IEA-USP para eventual consulta.

Recebido em 16.7.2009 e aceito em 21.8.2009. 